\title{
Kunstwerke im Palmengarten: „Perseus \& AndromedA“
}

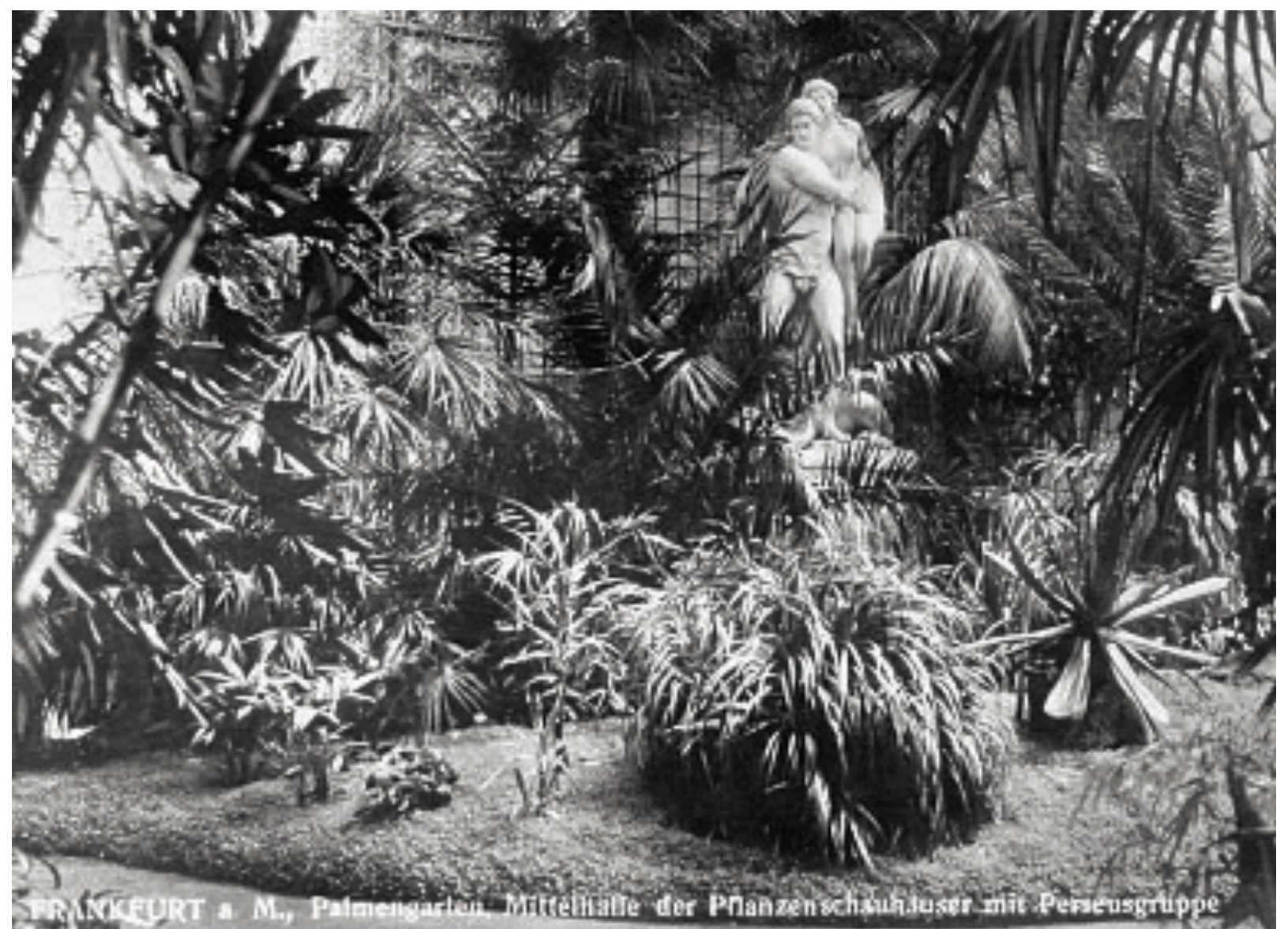

Zwischen den Tanzenden Wassern und der Liegewiese befindet sich im Palmengarten die vom Bildhauer Gustav Kaupert um 1890 geschaffene Marmor-Statue „Perseus und Andromeda“. Kaupert wurde 1866 als Professor und Nachfolger von Johann Nepomuk Zwerger an das Städelsche Kunstinstitut berufen. Er unterrichtete dort von 1887 bis 1892 die Bildhauerklasse.

Unsere Statue zeigt Perseus, der auf einem Drachen steht und Andromeda auf dem Arm hält. Laut griechischer Mythologie ist ANDroMEDA die Tochter des Königs der Aithiopen, Kepheus, und der Kassiopeia. Perseus rettet Andromeda, die an einem Felsen im Meer festgeschmiedet ist, vor einem Ungeheuer und nimmt sie zur Frau.

Die Statue wurde vom Chemiker, Industriellen und Mäzen Eugen Nicolaus von Lucius (1834?-1903) aus Höchst im Jahr 1906 dem
Palmengarten geschenkt. Anlass war die Einweihung der neuen Pflanzenschauhäuser (Mittelhalle). Alte Ansichtskarten, wie hier abgebildet, die die Statue in dem historischen Gewächshaus zeigen, sind gelegentlich noch bei Sammlern zu bekommen. Seit dem 13. Mai 1988 steht die Statue an ihrem jetzigen Standort, wo sie von der Firma Kohlmann aufgestellt wurde.

Abb. 1: Ansichtskarte aus dem Jahr 1930, die die Mittelhalle mit dem Kunstwerk zeigt.

Abb. 2 (Seite 77 oben links): Perseus und Andromeda an ihrem heutigen Standort in der Nähe der Tanzenden Wasser.

Abb. 3 (Seite 77 oben rechts): Perseus und Andromeda im Schneetreiben.

Abb. 4 (Seite 77 unten): In die Gesichter geschaut. 

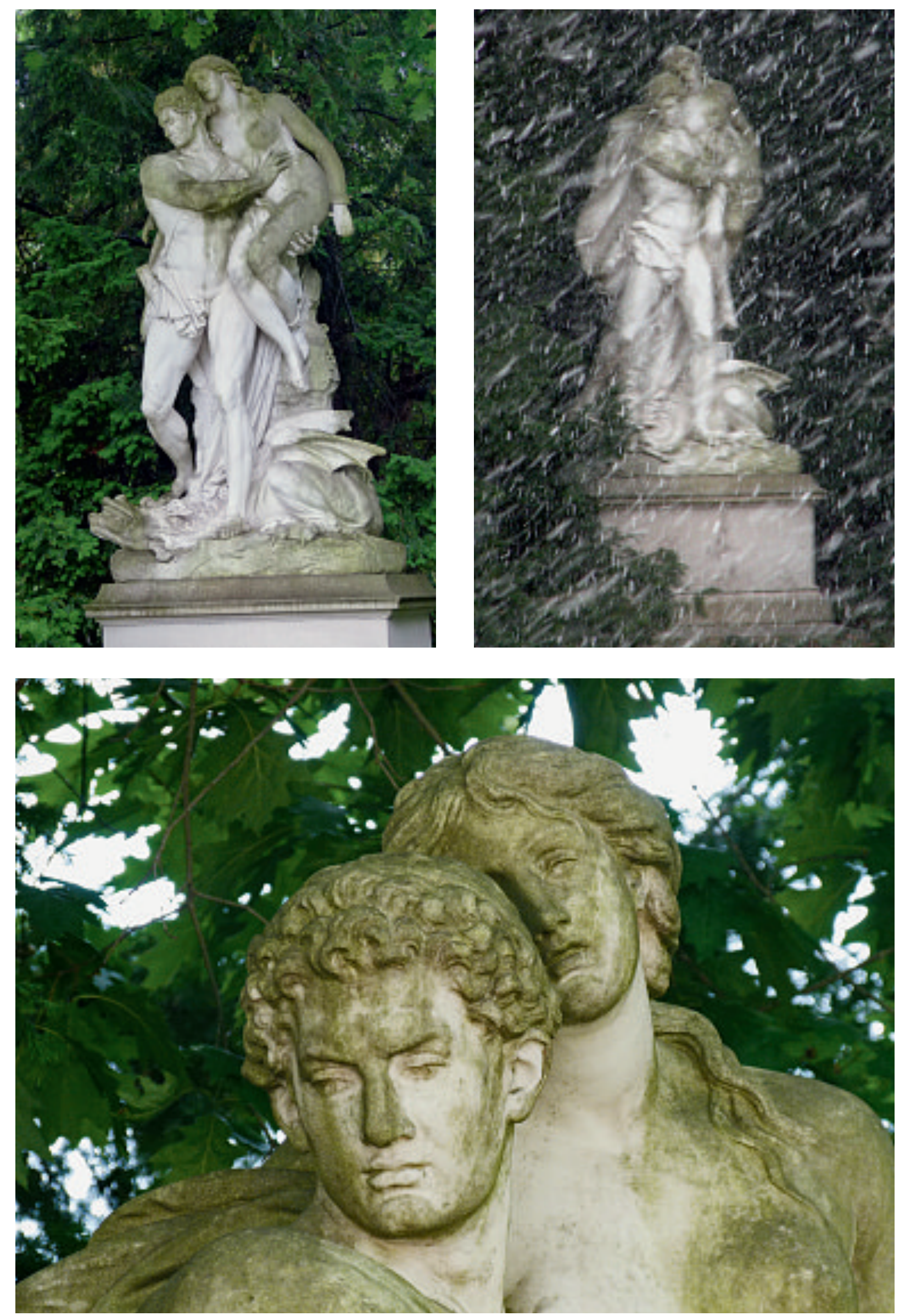


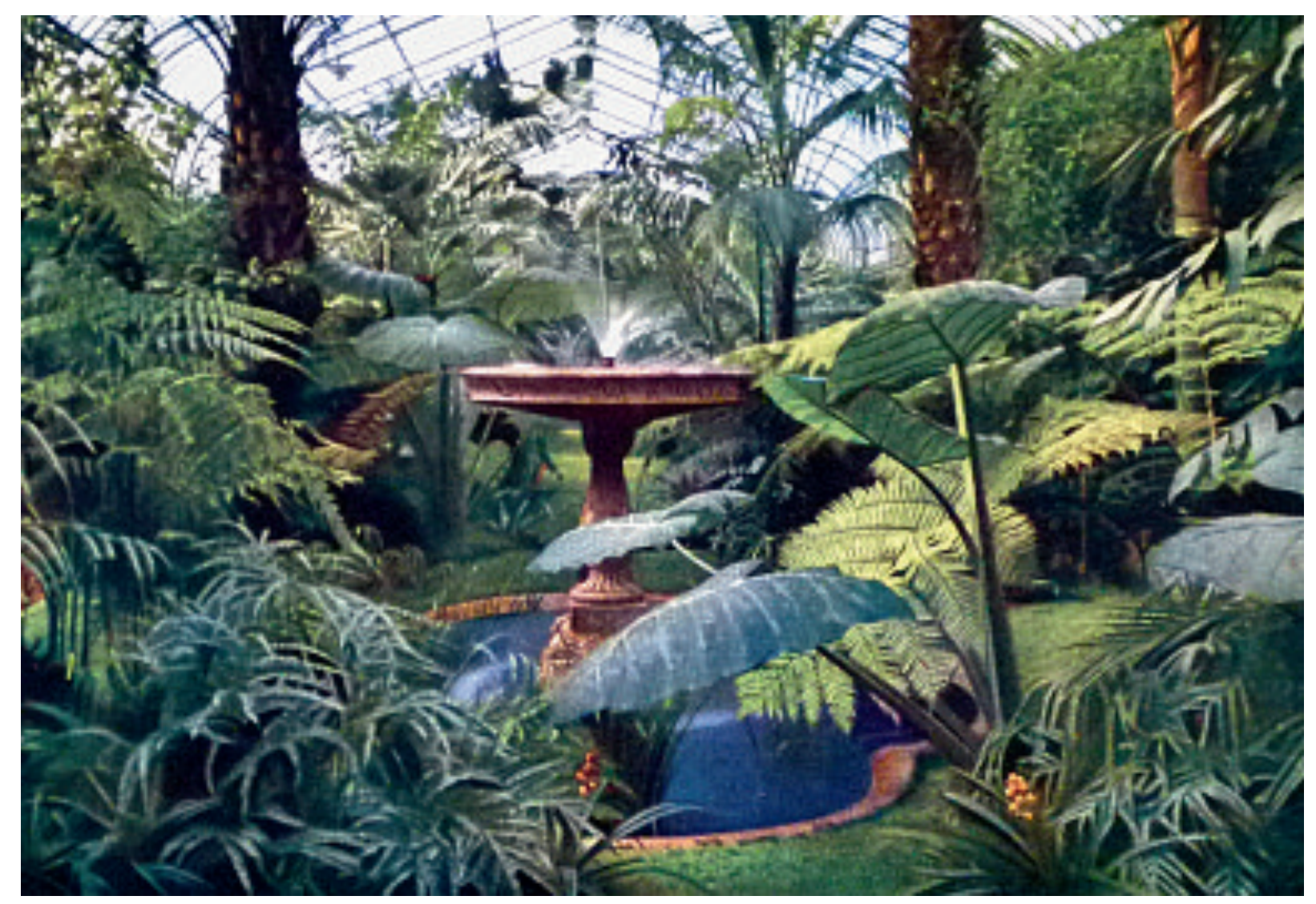

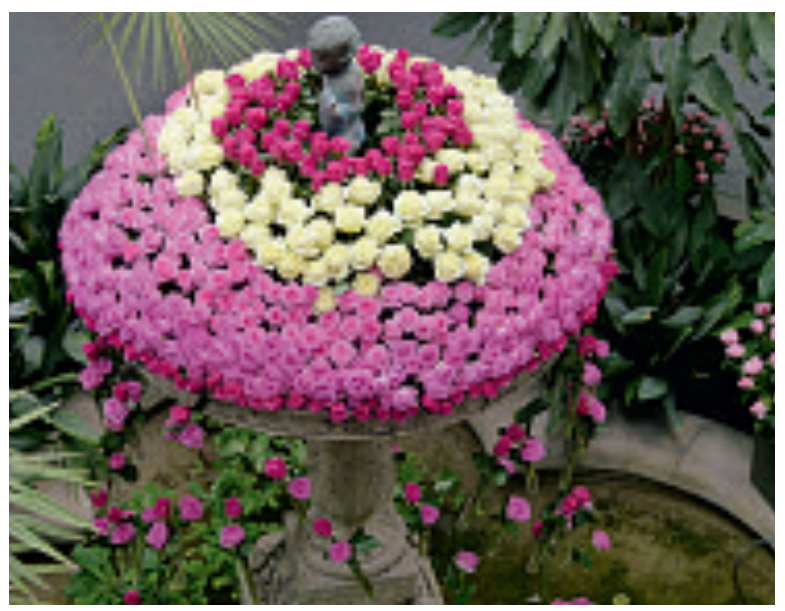

Während der verschiedenen Jahreszeiten, ob im Schnee oder bei Sonnenschein, haben „PerSEUs und ANDROMEDA“ ganz unterschiedliche Wirkungen auf den Betrachter.

Im heutigen Eingangsschauhaus, der umgebauten und räumlich versetzten Mittelhalle, befinden sich Perseus und Andromeda nicht mehr. Der historische Brunnen dagegen ist hier noch erhalten. Zum Rosen- und Lichterfest 2011 wurde er üppig mit Rosen geschmückt (siehe Foto). Dieses historische Gewächshaus wurde im Zuge der Erweiterung der Schauhausflächen gebaut. Direktor August Siebert setzte sich damals für eine neuartige Schauhausfläche statt der Vergrößerung des Palmenhauses ein. Nach sorgfältiger Planung wurde mit dem Neubau von $3500 \mathrm{~m}^{2}$ Hochglasfläche am 24. April 1905 begonnen. Bereits im Oktober war die gesamte Fläche eingedeckt. Am 5. und 6. Juni war es dann soweit, das Gewächshaus wurde im Rahmen eines großen Gartenfestes eröffnet.

Abb. 5 (oben): Mittelhalle, der ehemalige Standort von Perseus und Andromeda, auf einer historischen Ansichtskarte. In der Mitte der heute noch existierende Brunnen.

Abb. 6 (unten): „Mittelhallen-Brunnen“ im Eingangsschauhaus Siesmayerstraße, während des Rosenund Lichterfestes 2011 mit üppigem Rosenschmuck. 